\title{
Using Social Media for Research: The Role of Interactivity, Collaborative Learning, and Engagement on the Performance of Students in Malaysian Post-Secondary Institutes
}

\author{
Waleed Mugahed Al-rahmi ${ }^{1}$ \\ Mohd Shahizan Othman ${ }^{1}$ \\ Lizawati Mi Yusuf ${ }^{1}$ \\ Department of Information System, Faculty of computing, Universiti Teknologi Malaysia, Johor Bahru, 81310, Malaysia \\ Correspondence: Waleed Mugahed Al-rahmi, Department of Information System, Faculty of computing \\ Universiti Teknologi Malaysia, Johor Bahru, 81310, Malaysia. E-mail: abumunir82@yahoo.com
}

\author{
Doi:10.5901/mjss.2015.v6n5s2p536
}

\begin{abstract}
A great deal of research has been conducted regarding the effect of social media on research. However, only a few of these studies have examined the collaborative use of social media as a way to improve the performance of students. Both students and supervisors have expanded their use of social media and understanding how social media can be used to instigate improvements through collaborative learning must be investigated. We conducted a survey of two universities in Malaysia. The goal of this study was to identify the characteristics and factors of social media that improve the academic performance of postsecondary students and students through collaborative learning. Four hundred and twenty-six responses were received from the Malaysian universities surveyed. IBM SPSS and Amos were used to analyze the data. We used a constructivism theory to further explore the data. The results demonstrated that collaborative learning and engagement using social media had a significant and positive affect on the interactions and engagement of members and supervisors of research groups in Malaysian universities.
\end{abstract}

Keywords: social media, collaborative learning, engagement, academic performance, Higher education.

\section{Introduction}

The rapid growth of social media networking sites (SNS) such as Facebook, Linkedln, Myspace, Twitter, and Pinterest has resulted in researchers, educators, and students using these sites more frequently for a variety of purposes (Roblyer et al., 2010). Educators who believe that learning is a social endeavor (Vygotsky, 1978) have taken a keen interesting in SNS and its ability to support learning in formal (Cho et al., 2007) and informal environments (Greenhow et al., 2009). As a result, educators and policy makers have attempted to regulate and leverage SNS. Despite their importance, there is a lack of empirical literature on SNS even though academics recognized the challenges faced by educators who use social media for teaching purposes (Selwyn, 2009). It is especially important to understand how the engagement between educators and students using SNS for educational purposes might result in problematic outcomes for educator who uses social media for private matters.

In 2011, Facebook had over 800 million active users (Facebook,2011).The resources provided by Facebook have the potential to improve learning experiences in a variety of ways such as allowing for more efficient communication, providing a platform for positive social transformation, encouraging openness (Roblyer et al., 2010), learner participation, community building. Facebook also provides a venue for social presence (Mcloughlin et al., 2010). Despite these benefits, there is little empirical evidence for using SNS for educational purposes (Greenhow et al., 2009) leaving researchers at a disadvantage when it comes to advocating for using SNS for educational purposes. Furthermore, SNS online social networks are becoming more and more interconnected as they share information (Kim et al., 2013). Several educators remain reluctant to use SNS for educational purposes (Ajjan and Hartshorne, 2008) even in ways that align with traditional teacher centric technologies currently in use (Roblyer et al., 2010). In one study conducted by Junco (2012), the author discovered that there was a negative relationship between time spent on Facebook and the GPA of a college student. In other words, student's academic performance suffers when they are distracted by SNS such as YouTube and Google+ (Kasturi et al., 2014; Junco, 2012; Junco and Cotton, 2012; Paul et al., 2012). 
The principle goal of this study was to develop a framework that would identify the key factors of social media that had an impact on collaborative learning and ultimately the performance of students at Malaysian post-secondary institutions. In Section 2, the academic benefits and use of social media in post-secondary institutions is examined and the importance of social media is highlighted. Section 3 concentrates on the conceptual framework and hypotheses found in this paper. Section 4 provides a discussion of the methodology used in this study as well as a description of the respondents, data collection procedures, and measurement model. Section 5 concludes this paper by discussing the results, providing a conclusion, and suggestions for future work in this area.

\section{Using Social Media Tools in Higher Education}

Currently, there is no official definition of social media (Kaplan and Haenlein, 2010). The collaboration and resulting community of online systems of communication is known as social media and it may include social media networks, blogs, wikis, multimedia platforms, and virtual social worlds as discussed in the current literature (McEwan, 2011). Many social network sites (SNS), for example Facebook, Linkedin and Myspace, are recognized globally. SNS allow users to create their own profiles and content that can be shared with other users (Boyd and Ellison, 2007). Some researchers refer to SNS as Web 2.0 when they are discussing SNS (Gruzd, A.Wilk, 2010; Kaplan and Haenlein, 2010). As noted earlier, Facebook is one example of a SNS. Facebook allows users to easily send messages, add friends, create personal profiles, be part of a group, develop applications and content, and discover other users (Haase, 2010). Social media sites such as Facebook, Myspace, Twitter, and Linkedln use these abilities to link a user with other users of the same social media platform (Kim, 2011).

Early studies on social media provided information to a wide audience regarding Web 2.0 however, the entire audience has the ability to produce content and make the social media process interactive by using blogs, wikis, social bookmarking, media sharing services, collaborative editing tools, social networking, syndication, and modifications to the technology (McEwan, 2011).

Linkedln was launched in 2003 as a professional networking site. Linkedln provides a set of professional contacts linked by trust that illustrates an integrated continuum of connectivity and online contacts (Papacharissi, 2009). Linkedln remains a profitable tool for professional image building and the creation of inter-organizational value creation and collaboration (Brown, 2012). In 2004, Mark Zuckerberg was a student at Harvard University when he brought Facebook to the world (Jones et al., 2010).

\subsection{The Importance of Social Media}

Social media allows users to easily connect with groups while relinquishing control over their independent communications. Several media network sites including Facebook and Myspace allow their users to display their profile in the social network while managing the content of their own pages where they can post personal messages, create photo albums, find friends, and organize actions. In other words, the users of online social media networks can create their own websites and link them to other users making these sites attractive to institutions and organizations. For example, within an organization, a user can share documents, post messages, and connect with other employees and resources (Jiang and Tang, 2010). In an academic setting, Facebook can be used to minimize conflict between a student and teaching staff in a private setting (Selwyn, 2009). Social networking sites represent one of the most popular types of social software in use as countless users embrace Facebook, Linkedln, Myspace, and Twitter. Current research suggests that in addition to a social life outside of academia, the social media network used by international students facilitates their adjustment to learning in a foreign environment (Rienties et al., 2011; Zhou et al., 2008). Having friends from the their home culture and their host culture can positively affect an international student's social integration and academic performance (Montgomery and McDowell, 2008; Rienties et al., 2011; Russell et al., 2009).

\section{Conceptual Framework and Hypotheses}

This study explained the framework illustrated in Figure 1 that shows the impact of social media and collaborative learning at five research universities in Malaysia using constructivism theory. Figure 1 demonstrates that the integration of social media is linked to collaborative learning. The variables for social media included interactions between members of research groups (INRGM), interactions with supervisors (INSU), engagement (ENG), collaborative learning (CL), students' satisfaction (RS), and students' academic performance (PR). 


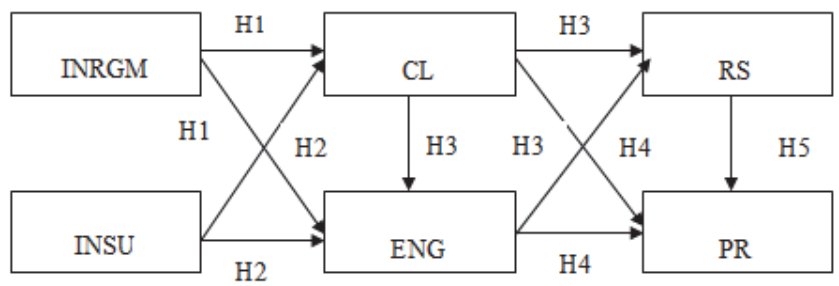

Figure 1. Conceptual framework

\subsection{Interactions between group members and supervisors}

When technology is used independently, it often does not result in learning (Aguilar-Roca et al., 2012). Additionally, prior computer experience plays a role in a student's perception of online learning methods (Top, 2012). Regardless of experience, the internet can provide an effective tool for managing the educational and learning activities of a student. Students enrolled in online courses also spend more time using online tools and social media to supplement their course work compared to students participating in a traditional classroom environment (Chen et al., 2010). Consequently, social media can present an environment that encourages critical thinking and collaboration for course work that is supplemented with outside materials and knowledge developed by a peer group (Carini et al., 2006; Mazman and Usluel, 2010). Facebook can be used as an effective learning platform that enhances student engagement and their overall learning experience while encouraging them to become active learners with a drive to learn and exchange ideas with other members of their learning community (Wang et al., 2012). According to (Kim et al., 2013), a dynamic influence between social networks helps to direct interactions between different social networks. Consequently, the development of actively engaged students and online virtual relationships using social media provides for learning opportunities as students are encouraged to connect with resources outside of the classroom (Fewkes and McCabe, 2012; Yu et al., 2010). This direct form of student interaction delivers many learning benefits (Haseman et al., 2002; Arcas and Ortega, 2013). Generally speaking, integration is very relevant to students who report to a supervisor or students at universities. The following hypotheses were tested in this study:

H1a: There is a significant relationship between group member interactions and collaborative learning.

$\mathrm{H} 1 \mathrm{~b}$ : There is a significant relationship between group member interactions and engagement learning.

$\mathrm{H} 2 \mathrm{a}$ : There is a significant relationship between group member interactions with their supervisors and collaborative

$\mathrm{H} 2 \mathrm{~b}$ : There is a significant relationship between group member interactions with their supervisors and engagement.

\subsection{Collaborative Learning Theory}

Collaborative learning occurs when individuals in a group cooperating to achieve shared learning objectives (Johnson et al., 2008). This type of learning can be understood by employing theories based on social interdependence, cognitive development, and behavioral learning. According to Johnson et al. (2008), collaborative learning is composed of the following five elements:

1. Positive interdependence

2. Individual accountability

3. Primitive interactions

4. Interpersonal and small group skills

5. Group processing

Collaborative learning requires planning of the part of the teacher to ensure that five elements are being addressed (Novak et al., 2012). In this study, the important role played by these five elements inspired the development of a conceptual framework that would demonstrate how social media can benefit collaborative learning (Yampinij et al., 2012).

The following hypotheses were used to test the influence of collaborative learning in this study:

$\mathrm{H} 3 \mathrm{a}$ : There is a significant relationship between collaborative learning and engagement.

$\mathrm{H} 3 \mathrm{~b}$ : There is a significant relationship between collaborative learning and students' satisfaction. 
$\mathrm{H} 3 \mathrm{c}$ : There is a significant relationship between collaborative learning and the performance of students.

\subsection{Engagement}

There are few studies that investigate the relationship between social media and student engagement in higher education but studies that examine the relationship between technology and engagement are increasing. Chen (2013) stated that post-secondary student who use e-voting systems were better able to answer math questions. Similarly, Annetta et al. (2009) found that students who played educational games that taught genetic concepts were more engaged than a control group. Additionally, Chen et al. (2010) used data from a national survey of student engagement and discovered that there was a significant relationship between the use of educational technology and student engagement. These studies have contributed to the body of literature on technology and engagement but they were limited in terms of how they measured engagement as they used only a single variable and a small number of participants. The following hypotheses were used to test the relationship between engagement, satisfaction, and performance.

$\mathrm{H} 4 \mathrm{a}$ : There is a significant relationship between engagement and students satisfaction.

$\mathrm{H} 4 \mathrm{~b}$ : There is a significant relationship between engagement and students' academic performance.

\subsection{Students' Satisfaction}

The use of social media by educators has an effect on perceived student satisfaction and learning outcomes. Yu et al. (2010) laid out the expected benefits and Aijan and Hartshorne (2008) asserted that there is a significant connection between student learning and satisfaction when social networking platforms were used for collaborative learning. Using social media in post-secondary institutions assures that students will receive a sufficient amount of knowledge and improve their performance (Vie, 2008). In some studies, evaluation periods were used to provide feedback for both the student and the educator, to determine the depth of knowledge possessed by the student, their satisfaction level, and to assess their overall performance (Forkosh and Hershkovitz, 2012). In almost every relevant study, the use of social media was positively associated with improvements in academic performance and satisfaction. The following hypotheses test this assertion:

H5: There is a significant relationship between students' satisfaction and students' academic performance.

\subsection{Social Media and Students' Academic Performance}

The question of whether or not social media benefits or harms a student's academic performance is part of a larger question associated with effects of social media on society in general. Other social media issues include the effects of social media on privacy, security, self-discipline, self-regulation, human adaptability, and the psychology of its users (Zwart et al., 2011; Anderson, 2012). In one study, Churchill (2009) demonstrated that blogs used for educational and social issues promoted a beneficial learning setting. In general, social media is seen to deliver benefits including increased social interactions through the use of e-media, access to information, increased creativity, the creation of a sense of belonging, the promotion of engagement and collaborative learning, the minimizing of barriers such as distance and socio-economic status in a group resulting in more interactions and communication between members, and improving the technological skills of users (Al-rahmi et al., 2015b; Zwart et al., 2011; Connolly, 2011; Hendrickson et al., 2011). Yet other studies have indicated that the use of Facebook is seen as an appropriate tool for interactions between teacher and students (Baran, 2010).

\section{Methodology}

This study relied on questionnaires to collect data. Consequently, a quantitative methodology was used, which is a reliable and accepted method for obtaining reliable information. The data collected using the questionnaires was quantitative in nature as it relied on numbers and statistics. The questionnaires were distributed to the participants and were designed to find an answer to the question, "What is the relationship between researchers and supervisors fostered by collaborative learning and the use of social media?" The questionnaire was distributed to 426 postgraduate students participating in the 2013-2014 academic session. The students were asked about their experiences and the impact of using social media on collaborative learning from a constructivism theory perspective. The respondents provide information regarding their experiences using social media tools. Three months after the questionnaires were distributed, 426 valid responses were collected from Universiti Teknologi Malaysia and the Universiti of Malaya. IBM SPSS (Version- 
20) and Amos (Version-16) were used to analyze the data.

\subsection{The Sample}

Sampling is a statistical procedure where a subset of individual observations regarding a population is selected. The sample selected to participate in this study represented students at post-secondary institutes in Malaysia. In the literature, two types of sampling are typically discusses. These two types are random and non-random sampling. In this study, a random sampling method was used to give each member of the target population an equal chance of being selected. The sample was composed of randomly selected postgraduate students from Universiti Teknologi Malaysia and the Universiti of Malaya. According to the sampling table developed by Morgan (1970) the number of respondents required for this study was 426.

\subsection{Data Collection and Measurement}

This study was part of a larger study that investigated the opinions held by students regarding the use of social media and collaborative learning to improve performance from a constructive theory perspective. The questionnaires used in this current study consisted of both open and close ended questions. There were 26 questions that were designed to collect background information, the respondent's reasons for using social media and their perception of what kind of influence social media had on their academic performance. The purpose of these questions was to measure the respondents' perception of how social media affected their academic performance. The final questionnaire was sent to 590 respondents and 426 of those respondents completed the survey by February 2014. In addition to asking questions related to the variables considered in the framework designed for this study, the questionnaire also include questions related to the respondents overall impression of social media related to interactions with members of their research group, supervisors, engagement, collaborative learning, their level of satisfaction, and their performance. They were also asked to describe the benefits of using this technology in terms of sharing knowledge, exchanging information, interacting with others, and collaborative learning. The purpose of these questions was to determine if social media increased the perceived quality of the interaction between the respondents and their supervisors (Ajjan and Hartshorne, 2008). The results indicated that the respondent's perception of the ease of use, usefulness, and intentions of social media encouraged them to continue to use social media, which lead to improving their active collaborative learning processes. Social media had a positive effect on the perceived quality of their interactions with their supervisors (Ajjan and Hartshorne, 2008). Interactions were observed over the course of this study because they are a critical aspect of the training process and the respondents are encouraged to participate in collaborative learning situations (So and Brush, 2008; Al-rahmi and Othman, 2013). The same assumption is the same for perceived ease of use, usefulness, and intention to use social media (Kim et al., 2007). In other words, ease of use, usefulness, and intention to use social media enhanced collaborative learning at universities and improved academic learning using social media for collaborative learning to improving students' academic performance (Al-rahmi et al., 2014; Yampinij et al., 2012).

This study has records the 26 questions used to measure the constructs used in the framework developed for this study. An interaction between group members was measured using five items recommended by Liu (2003) and McMillan and Hwang (2002). An interaction with supervisors was measured using four items inspired by Liu (2003) and McMillan and Hwang (2002). The four questions used to measure collaborative learning were adapted from So and Brush (2008). Four items were constructed to assess engagement and these were based on recommendations made by Gallini and Moely (2003) and Medlin and Green (2009). The items that investigated satisfaction were derived from the work of Moore (2009). Finally, academic performance was evaluated using questions based on the suggestions of MacGeorge et al. (2008).

Table 1: Discriminant validity

\begin{tabular}{ccccccc}
\hline & RS & INRGM & INSU & CL & EN & AP \\
\hline RS & $\mathbf{0 . 7 4 9}$ & & & & & \\
INRGM & 0.495 & 0.686 & & & & \\
INSU & 0.391 & 0.456 & 0.758 & & & \\
CL & 0.682 & 0.554 & 0.494 & 0.744 & & \\
EN & 0.488 & 0.546 & 0.523 & 0.696 & 0.668 & \\
AP & 0.659 & 0.574 & 0.512 & 0.629 & 0.607 & 0.647 \\
\hline
\end{tabular}

Note: RS: Researchers' Satisfaction; IN_GM: Interactive with Group Member; IN_SU: Interactive with Supervisor; IU: Intention to Use; CL: Collaborative learning; EN: Engagement and AP: Academic Performance. 
In this study, discriminant validity was measured using a correlation index, a crematory factor analysis, and Composite Reliability. The correlation index between variables in this study was less than 0.80 (Hair et al., 2010). The crematory factor analysis found that items with a factor loading of 0.5 or greater were acceptable and the Composite Reliability was $\geq 0.70$. Furthermore, the value of the average variance extracted (AVE) for each construct was equal to or greater than 0.5 , and square root AVE for each construct was higher than inter-construct correlations (IC) associated with that factor and the constructs. The Cronbachs alpha was $\geq 0.70$ (Hair et al., 2010; Fornell and Larcker, 1998).

\section{Data Analysis and Results}

The background of the respondents was also gathered by items in the questionnaire. Once the data from the questionnaire was analyzed, it was found that $203(47.7 \%)$ of the respondents were male and $223(52.3 \%)$ were female. The random sampling method used ensured that the higher number of female respondents was purely coincidental. The relationship between academic performance, collaborative learning, engagement, and social media was measured by examining the interactions between group members and with supervisors. The reliability of the survey was confirmed by a Cronback's alpha of 0.857 for the standardized items.

\subsection{Measurement Model Analysis}

The structural equation model (SEM) used as the primary statistical technique used to analyze the data. Confirmatory factor analysis (CFA) and Amos 16 were also used. The results of the analysis revealed the overall goodness-of-fit using fit Indices (X2, df, X2/df, RMR, IFI, TLI, CFI and RMSEA). CFA found that the overall model fit was acceptable. The results of the measurement model are shown in Table 2.

Table 2: Summary of Goodness Fit Indices

\begin{tabular}{llc}
\hline Type of measure & Acceptable level of fit & Value \\
\hline Chi-square $(X 2)$ & $\leq 3.5$ to 0 (perfect fit) and $(\rho>.01)$ & 385.971 \\
Normed Chi-square $(X 2)$ & Value should be greater than1.0 and less than 5.0 & 3.216 \\
Root-Mean Residual (RMR) & Close to 0 (perfect fit) & .050 \\
Incremental Fit Index ( IFI) & Value should be equal to or greater than 0.90. & .944 \\
Tucker Lewis Index (TLI) & Value should be equal to or greater than 0.90. & .928 \\
Comparative Fit Index (CFI) & Value should be equal to or greater than 0.90. & .944 \\
Root mean square error of & Value below 0.10 indicates a good fit and below 0.05 is deemed a very good fit. & .048 \\
approximation (RMSEA) & & \\
\hline
\end{tabular}

Source: Adapted from (Hair et al., 2010)

\subsection{Structural Model Analysis}

The next step of the SEM, a CFA was conducted to test the structural framework. Table 4 shows the structure of the framework and the model's key statistics, which are very good. As a result, the framework is valid and the results related to each hypothesis can be analyzed.

\subsection{The Results of Hypothesis Testing}

The results of this study confirmed the framework and the hypotheses regarding the directional link between the variables in the framework. The unstandardized coefficient parameters and the standard errors for the structural framework are shown in Table 3.

Table 3: Regression Weights

\begin{tabular}{|c|c|c|c|c|c|c|c|c|}
\hline $\mathrm{H}$ & Independent & Relationship & Dependent & Estimate & S.E. & C.R. & $\mathbf{P}$ & Result \\
\hline $\mathrm{H} 1 \mathrm{a}$ & INRGM & & $\mathrm{CL}$ & .300 & .037 & 8.025 & $\star \star * *$ & Supported \\
\hline $\mathrm{H} 2 \mathrm{a}$ & INSU & & $\mathrm{CL}$ & .273 & .029 & 9.268 & $* * *$ & Supported \\
\hline $\mathrm{H} 2 \mathrm{~b}$ & INSU & & ENG & .144 & .025 & 5.798 & $* * *$ & Supported \\
\hline
\end{tabular}




\begin{tabular}{cclcccccc}
\hline H1b & INRGM & $\longrightarrow$ & ENG & .276 & .031 & 8.876 & $* * *$ & Supported \\
H3a & CL & $\longrightarrow$ & ENG & .386 & .030 & 12.974 & $* * *$ & Supported \\
H3b & CL & RS & .315 & .032 & 9.688 & $* * *$ & Supported \\
H4a & ENG & $\longrightarrow$ & RS & .287 & .034 & 8.369 & $* * *$ & Supported \\
H4b & ENG & $\longrightarrow$ & PR & .194 & .035 & 5.519 & $* * *$ & Supported \\
H3c & CL & $\longrightarrow$ & .272 & .034 & 8.032 & $* * *$ & Supported \\
H5 & RS & PR & .376 & .036 & 10.323 & $* * *$ & Supported \\
\hline
\end{tabular}

C.R.: Critical Ratio or t-value

\subsection{Discussions and implications}

Table 3 and Figure 2 both illustrate the significant positive relationship between engagement and collaborative learning ( $\beta$ $=0.386, p<0.001$ ). These results confirm hypothesis $\mathrm{H} 3 \mathrm{a}$, which stated that there is a significant relationship between collaborative learning and engagement as seen by examining the interactions between group members and between group members and their supervisors using social media. The findings recorded in Table 2 support hypothesis H5 as there was a significant relationship between satisfaction and performance as interactions between group members or between group members and supervisors using social media and collaborative learning was positively related to engagement.

The results illustrated in Table 3 confirm that collaborative learning had a significant and positive relationship with satisfaction $(\beta=0.315, p<0.001)$. These findings support hypothesis $H 3 b$, which asserted that there is a significant relationship between collaborative learning and students' satisfaction and the subsequent performance of students who used social media to share information. Hypothesis $\mathrm{Hla}$ was also confirmed as interactions between group members had a significant and positive impact on collaborative learning $(\beta=0.300, p<0.001)$. Here the ability of group members to exchange information, share their knowledge and have discussions with other group members was enhanced by social media. The results captured in Table 4also support hypothesis $\mathrm{H} 4 \mathrm{a}$ that stated that there is a significant relationship between engagement and satisfaction. Likewise hypothesis $\mathrm{H} 1 \mathrm{~b}$ was confirmed as the results established the positive significant relationship $(\beta=0.276, p<0.001$ ) between interactions between group members and engagement. In other words, group members learned how to work effectively with other members of their group. Hypothesis $\mathrm{H} 2 \mathrm{a}$ was also supported by the results of the questionnaire as a significant relationship $(\beta=0.273, p<0.001)$ between inter actions with supervisors and collaborative learning was established as this relationship enhanced communication between supervisors and members of the research group.

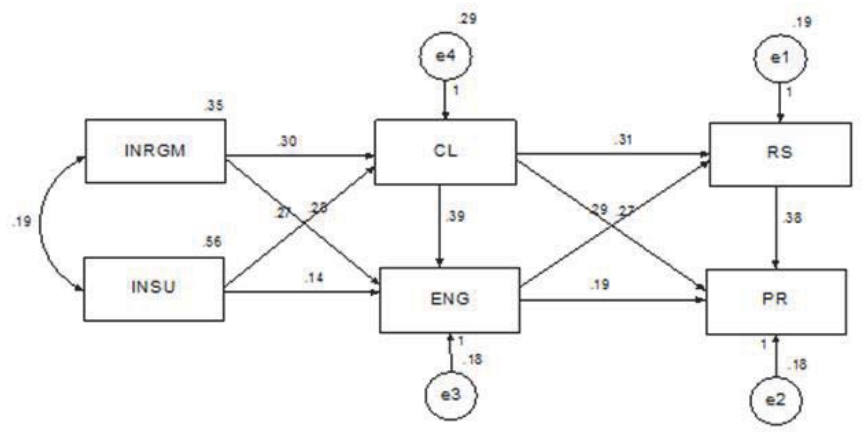

Figure 2. Results for Proposed Framework

The significant positive relationship between collaborative learning and the performance of the students as described by hypothesis $\mathrm{H} 3 \mathrm{c}$ was confirmed by the results of this study $(\beta=0.272, p<0.001)$. The active exchange of ideas between group members resulted in better problem solving and facilitated discussion with supervisors. Hypothesis $\mathrm{H} 4 \mathrm{~b}$ was also confirmed as there was proof of a significant positive relationship between engagement and performance $(\beta=0.194, p<$ 0.001). In other words, the performance of the participants improved when they were engaged and sharing information with their fellow group members and supervisors. The final hypothesis, hypothesis $\mathrm{H} 2 \mathrm{~b}$ was also confirmed as the interactions with supervisors had a significant positive affect on engagement $(\beta=0.144, p<0.001)$ highlighting the 
importance of sharing information and knowledge.

Table 5 shows that the Pearson correlation coefficient had a confidence level of $99 \%$. The best correlation was between students' satisfaction and performance (0.806). The following acronyms were using in Table 4:

- Interactions between research group members - INRGM

- Interactions between research group members and supervisors - INSU

- Engagement - ENG

- Collaborative Learning - $\mathrm{CL}$

- students' Satisfaction - RS

- students' academic Performance - PR

Table 4: Descriptive statistics and correlation matrix

\begin{tabular}{ccccccc}
\hline & INRGM & INSU & ENG & CL & RS & PR \\
\hline INRGM & 1 & & & & & \\
INSU & $.633^{* *}$ & 1 & & & & \\
ENG & $.728^{* *}$ & $.685^{* *}$ & 1 & & & \\
CL & $.625^{* *}$ & $.650^{* *}$ & $.806^{* *}$ & 1 & & \\
RS & $.625^{* *}$ & $.575^{* *}$ & $.731^{*+}$ & $.751^{* *}$ & 1 & \\
PR & $.664^{* *}$ & $.665^{* *}$ & $.751^{*+}$ & $.794^{* *}$ & $.806^{* *}$ & 1 \\
\hline
\end{tabular}

**. Correlation is significant at the 0.01 level (2-tailed).

The Pearson correlations show that the performance of the students was positively correlated with satisfaction $(r=0.806$, $P<0.01)$. The correlation between performance and collaborative learning was also significant and positive $(r=0.794, P<$ $0.01)$ as was the correlation between performance and engagement $(r=0.751, P<0.01)$, performance and interactions with supervisors $(r=0.665, P<0.01)$, and performance and interactions between group members $(r=0.664, P<0.01)$.

The results of this study reveal that the performance of the respondents depended on their interactions with other members of their group, their interactions with their supervisor, their engagement, and their level of satisfaction, which all contributed to their collaborative learning experience. In general, the use of social media provided a platform for collaborative learning and it was a useful tool as it allowed participants to complete quickly and efficiently complete tasks and conduct research. Incorporating social media into a group is easy and it facilitates communication between group members. The results of this study also demonstrated that the satisfaction of the respondents related to using social media for collaborative learning was high and that it helped improve their academic performance. Using social media to interact with supervisors resulted in a moderate level of satisfaction as social media provided a tool for collaborative learning that improved communication between supervisors as respondents allowing information to be more easily exchanged. Overall, the majority of participants in this study indicated that they would social media for collaborative learning and engagement thus further supporting hypotheses $\mathrm{H} 1 \mathrm{a}, \mathrm{H} 1 \mathrm{~b}, \mathrm{H} 2 \mathrm{a}, \mathrm{H} 2 \mathrm{~b}$ and $\mathrm{H} 3 \mathrm{a}$ and the results of previous studies (Al-rahmi et al.,2015; Al-rahmi et al.,2014; Yu et al.,2010; Al-rahmi et al., 2015c). However, these results contradicted the findings of Junco and Cotton (2012) and Madge et al. (2009).

Furthermore, the results of this study indicate that the use of social media will increase driven by a need for the user to remain informed activity in their social sphere.

In this study, the participants and supervisor who used social media for collaborative learning lead to improvements in their performance as they experienced high levels of engagement. The use of social media improved the confidence of the participants in this study and this lead to greater collaboration between group members and with their supervisors, which in turn increased the student's access to resources, information, and knowledge. Collaborative learning in this social media environment was more effective than face-to-face learning because it allowed participants to develop research skills through collaboration with other group member and to actively exchange ideas. The participants used social media to access resources held by their supervisor and they stated that they would use alternate forms of social media if it had better functionalities. The participants also indicated that they would use social media to improve their research skills and to build relationships with their supervisors thus further improving their academic performance while facilitating academic activities and cooperating with other researchers. As a result of these findings, hypotheses $\mathrm{H} 3 \mathrm{~b}, \mathrm{H} 3 \mathrm{c}, \mathrm{H} 4 \mathrm{a}, \mathrm{H} 4 \mathrm{~b}$ and $\mathrm{H} 5$ are confirmed, which agrees with the results of several past studies (Ainin et al., 2015; Alrahmi et al., 2015a; Al-rahmi et al., 2014; Alloway and Alloway, 2012; Al-rahmi et al., 2015b; Al-rahmi et al., 2015c) but contradicts the findings of past studies that suggested that the frequent use of social media harms academic performance (Kirschner et al., 2010). 
According to Mazmanand Usluel (2010), educational institutions should incorporate social media tools to improve student performance. In a learning environment, social media can enhance learning management systems, student engagement, and learning outcomes. The results of the current study contribute to current work in this field by reconciling the mixed feelings surrounding the use of social media by highlighting the important advantages gained by the type and quality of social media interactions. This study made two specific contributions. The first contribution is the field of constructivism theory in academic research. The second contribution is more practical as it provides educational departments and faculties, research management units, and government ministries with knowledge related to the beneficial use of social media as a way to encourage collaborative learning, engagement, interaction, and ultimately, academic performance.

\subsection{Conclusion and Future Work}

The benefits of social media in an academic setting to students and researchers are various. For example, social media improves the interactions between peers leading to greater diversity and improved communication between students, teachers, researchers, and supervisors. Social media also facilitates discussion and information sharing, which subsequently leads to a better understanding of the content. Additionally, students and researchers can access research materials and new information using collaborative learning. Overall, social media enhances the performance of all those involved in the educational system including students, teachers, and supervisors. It is recommended that future studies investigate additional elements that could be used to measure factors that influence performance and engagement while using collaborative learning in post-secondary settings.

\section{Acknowledgements}

This material is based upon work supported by The World Academy of Sciences (TWAS), Research Grant Agreement (RGA), under No: 14-317 RG/ITC/AS_C-- UNESCO FR: 3240283418.Also supported by Faculty of Marine, Hudaidah University, Hudaidah, Yemen.

\section{References}

Ainin, S. Naqshbandi, M. Mogavvemi S. \& Jaafar. N. (2015). Facebook usage, socialization and academic performance. Computers \& Education, 83 (2015) 64-73.

Alloway, T. \& Alloway. R. (2012). The impact of engagement with social networking sites (SNSs) on cognitive skills. Computers in Human Behavior, 28(5), 1748-1754.

Al-rahmi, W. \& Othman, M. (2013).The Impact of Social Media use on Academic Performance among university students: A Pilot Study, Journal of information systems research and innovation, 2013.

Al-rahmi, W. Othman, M. \& Musa, M. (2014). The Improvement of Students' Academic Performance by Using Social Media through Collaborative Learning in Malaysian Higher Education, Asian Social Science; Published by Canadian Center of Science and Education, Vol. 10, No. 8.

Al-rahmi, W. M. Othman, M.S. Yusof, L.M \& Musa. M.A. (2015a). Using Social Media as a Tool for Improving Academic Performance through Collaborative Learning in Malaysian Higher Education. Review of European Studies, 7(3), p265.

Al-rahmi, W. M., Othman, M. S., \& Yusuf, L. M. (2015b). Social Media for Collaborative Learning and Engagement: Adoption Framework in Higher Education Institutions in Malaysia. Mediterranean Journal of Social Sciences,6(3 S1), 246.

Al-rahmi, W. M., Othman, M. S., \& Yusuf, L. M. (2015c). The Effect of Social Media on Researchers' Academic Performance through Collaborative Learning in Malaysian Higher Education. Mediterranean Journal of Social Sciences, Vol 6 No 4( S1), 193.

Aguilar-Roca, M. Williams, E. \& O'Dowd, K. (2012). The impact of laptop-free zones on student performance and attitudes in large lectures, Computers \& Education, 59, 1300-1308.

Ajjan, H. \& Hartshorne, R. (2008). Investigating faculty decisions to adopt Web 2.0 technologies: Theory and empirical tests. Internet and Higher Education, 11, 71-80.

Anderson, Q. (2012).Millennia's will benefit and suffer due to their hyper connected lives.2012.

Annetta, A. Minogue, J. Holmes, Y. \& Cheng, T. (2009).Investigating the impact of video games on high school students' engagement and learning about genetics, Computers \& Education, 53, 74-85.

Arcas, B. \& Ortega, S. (2013). Using clickers in class. The role of interactivity, active collaborative learning and engagement in learning performance, Computers and Education, 62, 102-110.

Baran, B. (2010). Facebook as a formal instructional environment. British Journal of Educational Technology, 41(6), E146-E149.

Boyd, M. \& Ellison, B. (2007). Social Network Sites: Definition, History, and Scholarship, Journal of Computer-Mediated Communication, 13(1), 210-230.

Brown, S.(2012). Seeing Web 2.0 in context: A study of academic perceptions, The Internet and Higher Education, 15(1), 50-57. 
Cao, Y. \& Hong, P. (2011).Antecedents and consequences of social media utilization in college teaching: a proposed model with mixedmethods investigation, 2011, 19(4), 297-306.

Carini, M. Kuh, D. \& Klein, P. (2006).Student engagement and student learning: Testing the linkages, Research in Higher Education, 47(1), 1-32.

Chen, D. Lambert, D. \& Guidry, R. (2010). Engaging online learners: The impact of web-based technology on college student engagement, Computer \& Education, 54, 1222-1232.

Chen, R. (2013).Member use of social networking sites - an empirical examination, Decision Support Systems, 54(3), $1219-1227$.

Cho, H. Gay, G. Davidson, B. \& Ingraffea, A. (2007).Social networks, communication styles, and learning performance in a CSCL community, Computers \& Education , 49(2), 309-329.

Churchill, D. (2009). Educational applications of Web 2.0: using blogs to support teaching and learning. British Journal of Educational Technology, 40(1), 179-183.

Connolly, M. (2011). Benefits and Drawbacks of Social Media in Education, 2011, 1-20.

Fewkes, M. \& McCabe, M. (2012). Facebook: Learning tool or distraction, Journal of Digital Learning in Teacher Education, 28(3), 92-98.

Forkosh-Baruch, A. \& Hershkovitz, A. (2012).A case study of Israeli higher-education institutes sharing scholarly information with the community via social networks, The Internet and Higher Education, 15.

Fornell C. \& Larcker. D.F. (1998). Evaluating structural equation models with unob-servable variables and measurement error. Journal of Marketing Research, 18(1), 39-50.

Gallini S. M. \& Moely. B. E. (2003). Service-learning and engagement, academic challenge and retention. Michigan Journal of Community Service Learning, 5-14, Fall.

Greenhow, C. Robelia, B. \& Hughes, E. (2009). Learning, teaching, and scholarship in a digital age: web 2.0 and classroom research: what path should we take now, Educational Researcher, 38(4), 246-259.

Gruzd, A. \& Wilk, A.(2010). Tenure and Promotion in the Age of Online Social Media,2010.

Haase, Y. (2010). Uses and Gratifications of Social Media: A Comparison of Facebook and Instant Messaging, Bulletin of Science, Technology \& Society, 2010.

Hair, J. F. Black, W. C. Basin, B.J. \& Anderson. R.E. (2010). Multivariate data Analysis. (7th ed.). New Jersey: Upper Saddle River, Pearson Prentice Hall.2010.

Haseman, D. Polatoglu, N. \& Ramamurthy, K. (2002). An empirical investigation of the influences of the degree of interactivity of useroutcomes in a multimedia environment, Information Resources Management Journal, 15(2), 31-48.

Hendrickson, B. Rosen, D. \& Aune, K. (2011).An analysis of friendship networks, social connectedness, homesickness, and satisfaction levels of international students, International Journal of Intercultural Relation, 35(3), 281-295.

Jiang, H. \& Tang, M. (2010). Web-Based Learning Platforms Integrating Social Networking for Design Education at High Schools in China, International Conference on Computational Intelligence and Software Engineering, 2010.

Johnson, W. Johnson, T. Stanne, B. (2008).Cooperative Learning Methods: A Meta -Analysis. 2008.

Jones, N. Blackey, H. Fitzgibbon, K. \& Chew, E. (2010). Get out of MySpace, Computers and Education, 54(3), 776-782.

Junco, R. (2012). The relationship between frequency of Facebook use, participation in Facebook activities, and student engagement, Computers \& Educatio, 58(1), 162-171.

Junco, R., Elavsky, C. M., \& Heiberger, G. (2012). Putting twitter to the test: Assessing outcomes for student collaboration, engagement and success. British Journal of Educational Technology, 1-15.

Junco, R. \& Cotten, R. (2012). A 4 U: The relationship between multitasking and academic performance,Computers \& Education, 59(2), 505-514.

Kaplan, M. \&Haenlein, M. (2010). Users of the world, unite The challenges and opportunities of Social Media, Business Horizons, 53(1), 59-68.

Kasturi, V. Noor Fahrahin , F. \& Chiam , Y. (2014).Facebook Filter: Create Awareness among Users, The 3rd International Conference on Computer Science and Computational Mathematics, 2014, (ICCSCM 2014),2014.

Kim, B. (2011). Understanding antecedents of continuance intention in social-networking services, Cyberpsychology, behavior and social networking), 14(4).

Kim , M. Newth, D. \& Christen, P. (2013). Modeling Dynamics of Diffusion Across Heterogeneous Social Networks: News Diffusion in Social Media. Entropy, 15, 4215-4242, 17 September.

Kim, W. Chan, C. \& Gupta, S. (2007). Value-based adoption of mobile internet: An empirical investigation, Decision Support Systems, 43, 111-126.

Kirschner, J., Erkens, F., Kirschnker, G., \& Paas. F. (2010). Making the black box of collaborative learning transparent: Combining process-oriented and cognitive load approaches. Educational Psychology Review, 22, 139-154.

Liu. Y. (2003).Developing a scale to measure the interactivity of websites. Journal of Advertising Research, 43(3), 207-216.

MacGeorge, E. L, Homan, S. R Dunning, J. B Elmore, D Bodie, G.D \& Evans. E. (2008). The influence of learning characteristics on evaluation of audience response technology. Journal of Computing in Higher Education, 19, 25-46.

Madge, C, Meek, J., Wellens J. \& Hooley T.(2009). Facebook, social integration and informal learning at university: It is more for socializing and talking to friends about work than for actually doing work. Learning, Media and Technology, 34(2), 141-155.

Mazman, G. Usluel, K. (2010). Modeling educational usage of Facebook, Computers \& Education, 55, 444-453.

Medlin B. \& Green, K. W. (2009). Enhancing performance through goal setting, engagement, and optimism. Industrial Management \& Data Systems, 109(7), 943-956. 
McEwan, B. (2011). Managing Boundaries in the Web 2.0 Classroom, 2011 ,(131), 15-28.

Mcloughlin, C. \& Lee, W. (2010). Personalized and self-regulated learning in the Web 2. 0 eras, International exemplars of innovative pedagogy using social software, 26(1), 28-43.

McMillan, S. J. \& Hwang. J. (2002). Measures of perceived interactivity: an exploration of the role of direction and communication, user control and time in shaping perceptions of interactivity. Journal of Advertising, 31(3), 29-42.

Montgomery, C. \& McDowell, L. (2008).Social Networks and the International Student Experience: An International Community of Practice, Journal of Studies in International Education, 13(4), 455-466.

Moore. J.(2009). A synthesis of Sloan-C effective practices: December 2009. Journal of Asynchronous Learning Networks, 13(4), 84-94.

Novak, E. Razzouk, R. \& Johnson, E. (2012). The educational use of social annotation tools in higher education : A literature review, The Internet and Higher Education, 15(1), 39-49.

Papacharissi, Z. (2009).The virtual geographies of social networks: a comparative analysis of Facebook, Linkedln and A Small World, New Media \& Society, 11(1-2), 199-220.

Paul, A. Baker, M. \& Cochran, D. (2012). Effect of online social networking on student academic performance. Computers in Human Behavior, 28(6), 2117-2127.

Rienties, B. Beausaert, S. Grohnert, T. Niemantsverdriet, S. \& Kommers, P. (2011). Understanding academic performance of international students: the role of ethnicity, academic and social integration, Higher Education, 63(6), 685-700.

Roblyer, D. McDaniel, M. Webb, M. Herman, J. \& Witty, V. (2010) Findings on Facebook in higher education: A comparison of college faculty and student uses and perceptions of social networking sites, The Internet and Higher Education ,13(3), 134-140.

Russell, J. Rosenthal, D. \& Thomson, G. (2009). The international student experience: three styles of adaptation, Higher Education, 60(2), 235-249.

Selwyn, N.(2009).Faceworking: exploring students' education-related use of Facebook, Learning, Media and Technology,34(2), 157174.

So, J. \& Brush, A. (2008). Students' perceptions of collaborative learning, social presence and satisfaction in a blended learning environment: relationships and critical factors, Computers \& Education, 51(1), 318-336.

Top, E. (2012). Blogging as a social medium in undergraduate courses: Sense of community best predictor of perceived learning, Internet and Higher Education, 15, 24-28.

Vie, S. (2008).Digital Divide 2.0: Generation M and Online Social Networking Sites in the Composition Classroom, Computers and Composition, 25(1), 9-23.

Vygotsky, S. (1978). Mind in Society. Cambridge, MA: Harvard University Press, 1978.

Wang, Q., Woo, H. L., Quek, C. L., Yang, Y., \& Liu, M. (2012). Using the Facebook group as a learning management system: An exploratory study.British Journal of Educational Technology, 43(3), 428-438.

Yampinij, S. Sangsuwan, M. \& Chuathong, S. (2012). A conceptual framework for social network to support collaborative learning ( SSCL ) for enhancing knowledge construction of grade 3 students, 46.

Yu, Y. Tian, W. Vogel, D. \& Kwok, C. (2010). Can learning be virtually boosted?: An investigation of online social networking impacts, Computers \& Education, 55, 1494-1503.

Zhou, Y. Jindal , S. Topping, K. \& Todman, J. (2008). Theoretical models of culture shock and adaptation in international students in higher education, Studies in Higher Education, 33(1), 63.

Zwart, D. Lindsay, D. \& Phillips, M. (2011).Legal Risks and Social Networking Sites.2011. 